\title{
Coffee Consumption and Risk for Type 2 Diabetes Mellitus
}

\section{Citation}

Salazar-Martinez, Eduardo, Walter C. Willett, Alberto Ascherio, JoAnn E. Manson, Michael F. Leitzmann, Meir J. Stampfer, and Frank B. Hu. 2004. "Coffee Consumption and Risk for Type 2 Diabetes Mellitus." Annals of Internal Medicine 140 (1): 1. https:// doi.org/10.7326/0003-4819-140-1-200401060-00005.

\section{Permanent link}

http://nrs.harvard.edu/urn-3:HUL.InstRepos:41293017

\section{Terms of Use}

This article was downloaded from Harvard University's DASH repository, WARNING: This file should NOT have been available for downloading from Harvard University's DASH repository.

\section{Share Your Story}

The Harvard community has made this article openly available.

Please share how this access benefits you. Submit a story.

Accessibility 


\section{Coffee Consumption and Risk for Type 2 Diabetes Mellitus}

Eduardo Salazar-Martinez, MD, PhD; Walter C. Willett, MD, DrPH; Alberto Ascherio, MD, DrPH; JoAnn E. Manson, MD, DrPH; Michael F. Leitzmann, MD, DrPH; Meir J. Stampfer, MD, DrPH; and Frank B. Hu, MD, PhD

Background: In small, short-term studies, acute administration of caffeine decreases insulin sensitivity and impairs glucose tolerance.

Objective: To examine the long-term relationship between consumption of coffee and other caffeinated beverages and incidence of type 2 diabetes mellitus.

Design: Prospective cohort study.

Setting: The Nurses' Health Study and Health Professionals' Follow-up Study.

Participants: The authors followed 41934 men from 1986 to 1998 and 84276 women from 1980 to 1998. These participants did not have diabetes, cancer, or cardiovascular disease at baseline.

Measurements: Coffee consumption was assessed every 2 to 4 years through validated questionnaires.

Results: The authors documented 1333 new cases of type 2 diabetes in men and 4085 new cases in women. The authors found an inverse association between coffee intake and type 2 diabetes after adjustment for age, body mass index, and other risk factors. The multivariate relative risks for diabetes according to regular coffee consumption categories $(0,<1,1$ to 3,4 to 5 , or $\geq 6$ cups per day) in men were $1.00,0.98,0.93,0.71$, and 0.46 ( $95 \% \mathrm{Cl}, 0.26$ to $0.82 ; P=0.007$ for trend), respectively. The corresponding multivariate relative risks in women were 1.00, $1.16,0.99,0.70$, and $0.71(\mathrm{Cl}, 0.56$ to $0.89 ; P<0.001$ for trend), respectively. For decaffeinated coffee, the multivariate relative risks comparing persons who drank 4 cups or more per day with nondrinkers were $0.74(\mathrm{Cl}, 0.48$ to 1.12$)$ for men and $0.85(\mathrm{Cl}$, 0.61 to 1.17 ) for women. Total caffeine intake from coffee and other sources was associated with a statistically significantly lower risk for diabetes in both men and women.

Conclusions: These data suggest that long-term coffee consumption is associated with a statistically significantly lower risk for type 2 diabetes.

Ann Intern Med. 2004;140:1-8.

www.annals.org
$\mathbf{T}$ he prevalence of type 2 diabetes mellitus has increased dramatically in the past decades, and the disease now affects approximately $8 \%$ of U.S. adults (1). Diet and lifestyle factors are primary determinants of risk for type 2 diabetes (2). In addition to overweight and obesity, other independent behavioral and lifestyle factors include physical inactivity, smoking, and a diet higher in glycemic load and trans fatty acids and lower in fiber and polyunsaturated fatty acids. Coffee consumption may be related to diabetes because short-term metabolic studies have suggested that caffeine adversely affects insulin sensitivity and glucose metabolism (3). Coffee consumption is widespread; more than $50 \%$ of Americans drink coffee, and average per capita intake is about 2 cups per day (4). Coffee is the primary source of caffeine intake, providing approximately $210 \mathrm{mg} / \mathrm{d}$ per person in the United States.

In humans, acute administration of caffeine decreases insulin sensitivity and impairs glucose tolerance $(3,5-8)$. On the other hand, caffeine stimulates thermogenesis and increases energy expenditure (9-11), which may facilitate weight reduction and maintenance. Because of these complex physiologic effects of caffeine and because tolerance to the humoral and hemodynamic effects of caffeine typically develops with long-term use (12), it is difficult to extrapolate findings from short-term metabolic studies to longterm use of coffee and other caffeinated beverages.

A recent epidemiologic study has found a statistically significant inverse association between coffee consumption and risk for type 2 diabetes in a sample of Dutch participants (13). After adjustment for potential confounders, the relative risk for type 2 diabetes among participants con- suming at least 7 cups of coffee per day as compared with those consuming 2 cups or less per day was 0.50 (95\% CI, 0.35 to $0.72 ; P<0.001$ for trend). The study, however, could not distinguish regular coffee from decaffeinated coffee and did not evaluate the association with total caffeine intake.

In our study, we examined long-term intake of coffee and other caffeinated beverages and decaffeinated coffee in relation to incidence of type 2 diabetes in 2 large prospective cohorts of men and women. In particular, we examined whether the associations were modified by smoking and body mass index.

\section{Methods}

Study Sample

The Health Professionals Follow-up Study

The Health Professionals Follow-up Study (HPFS) was established in 1986 when 51529 male health professionals, including dentists, optometrists, veterinarians, osteopathic physicians, podiatrists, and pharmacists, who were 40 to 75 years of age returned a mailed questionnaire providing detailed information about their medical history, lifestyle, and other risk factors (14). Information on the cohort is updated every 2 years to identify newly diagnosed diseases. For our analysis, we excluded men with a previous diagnosis of type 2 diabetes, coronary heart disease, or cancer at baseline. Participants who did not complete more than 70 of 131 food items in the 1986 dietary questionnaire or had extreme scores for total daily intake of energy $(<800 \mathrm{kcal}$ or $>4200 \mathrm{kcal})$ were excluded. After exclu- 


\section{Context}

A recently published study in a Dutch population identified an association between higher coffee consumption and lower risk for type 2 diabetes mellitus but did not distinguish between intake of regular and decaffeinated coffee.

\section{Contribution}

This large epidemiologic study in a U.S. sample confirmed the Dutch study findings. It also found a statistically significant protective association between total caffeine intake and type 2 diabetes mellitus and a modest inverse association with decaffeinated coffee consumption.

\section{Implications}

Consumption of caffeinated coffee is associated with a reduced risk for type 2 diabetes mellitus. Further studies should explore the long-term effects of caffeine on glucose metabolism.

-The Editors

sions, the analysis included 41934 eligible men who were followed from 1986 to 1998.

\section{The Nurses' Health Study}

The Nurses' Health Study (NHS) was established in 1976 when 121700 female nurses 30 to 55 years of age living in 11 large states completed a mailed questionnaire providing detailed information about their medical history, lifestyles, and other risk factors (15). The information is updated every 2 years to identify newly diagnosed diseases. In 1980, a semiquantitative food frequency questionnaire was added. For our analysis, we excluded women with a previous diagnosis of type 2 diabetes, coronary heart disease, or cancer at baseline. Participants who did not complete more than 10 items on the 1980 dietary questionnaire or had extreme scores for total daily intake of energy $(<500 \mathrm{kcal}$ or $>3500 \mathrm{kcal})$ were also excluded, leaving 84276 eligible women who were followed from 1980 to 1998.

\section{Assessment of Coffee and Caffeine Intake}

Validated dietary questionnaires were sent to the HPFS participants in 1986, 1990, and 1994 and to the NHS participants in 1980, 1984, 1986, 1990, and 1994. In all the questionnaires, participants were asked how often on average during the previous year they had consumed coffee and tea. Decaffeinated coffee and different types of caffeinated soft drinks were first assessed in 1986 in the HPFS and in 1984 in the NHS. We assessed the total intake of caffeine by summing the caffeine content for a specific amount of each food during the previous year (1 cup for coffee or tea, one 12-ounce bottle or can for carbonated beverages, and 1 ounce for chocolate) multiplied by a weight proportional to the frequency of its use. The participants could choose from 9 frequency responses (never, 1 to 3 per month, 1 per week, 2 to 4 per week, 5 to 6 per week, 1 per day, 2 to 3 per day, 4 to 5 per day, and 6 or more per day). Using the U.S. Department of Agriculture food composition sources, we estimated that the caffeine content was $137 \mathrm{mg}$ per cup of coffee, $47 \mathrm{mg}$ per cup of tea, $46 \mathrm{mg}$ per bottle or can of cola beverage, and 7 $\mathrm{mg}$ per serving of chocolate candy. In our validation studies, high correlations were recorded for coffee and other caffeinated beverage intake assessed by the food frequency questionnaire and several 1-week diet records (coffee, $r=$ 0.78; tea, $r=0.93$; and caffeinated sodas, $r=0.85)(16)$.

For these analyses, coffee consumption was categorized into 5 groups: never, less than 1 cup per day, 1 to 3 cups per day, 4 to 5 cups per day, and 6 cups or more per day. Caffeine intake was categorized into quintiles.

\section{Assessment of Diabetes Cases}

Participants who reported having diabetes were sent a supplementary mailed questionnaire that asked about symptoms, diagnostic tests, and treatment. We considered any 1 of the following criteria to represent a new case of diabetes: classic symptoms and elevated glucose levels (fasting plasma glucose concentration $\geq 7.8 \mathrm{mmol} / \mathrm{L}[\geq 140$ $\mathrm{mg} / \mathrm{dL}]$ or randomly measured concentration $\geq 11.1$ $\mathrm{mmol} / \mathrm{L}[\geq 200 \mathrm{mg} / \mathrm{dL}]$ ); at least 2 elevated plasma glucose concentrations on different occasions in the absence of symptoms (plasma glucose level $\geq 11.1 \mathrm{mmol} / \mathrm{L}[\geq 200$ $\mathrm{mg} / \mathrm{dL}] 2$ or more hours after oral glucose tolerance testing); or treatment with oral hypoglycemic agents or insulin. Our criteria for diabetes classification are consistent with those proposed by the National Diabetes Data Group (17) because most cases were diagnosed before 1997.

The validity of this diagnostic procedure has been verified in a subsample of this study sample (18). The diagnosis of type 2 diabetes was confirmed by medical records in $98 \%$ of the participants. In addition, another substudy assessing the prevalence of undiagnosed diabetes suggested a very low rate of false-negative results (19).

\section{Statistical Analysis}

We calculated the follow-up period from the return of the baseline questionnaires (in 1986 for men and in 1980 for women) to the diagnosis of type 2 diabetes, death, or the end of follow-up (January 1998 for men and June 1998 for women), whichever occurred first.

Incidence rates for diabetes were calculated by dividing incident cases by person-years of follow-up in each category of coffee intake. Relative risks were calculated as the rate of occurrence of type 2 diabetes in each quintile of caffeine intake divided by the corresponding rate in the lowest quintile, and 95\% CIs were calculated. To inspect potential confounding variables for the analyses, we examined baseline characteristics (directly standardized to the age distribution of each cohort) according to coffee consumption levels. We used proportional hazards models (20) to adjust for several risk factors, including age in 5 categories $(<50,50$ to 54,55 to 59,60 to 64 , or $\geq 65$ 
Coffee and Diabetes Mellitus ARTICLE

Table 1. Baseline Characteristics according to Coffee Consumption Levels among Participants in the Health Professionals Follow-up Study and the Nurses' Health Study*

\begin{tabular}{|c|c|c|c|c|c|c|c|c|c|c|}
\hline \multirow[t]{2}{*}{ Characteristic } & \multicolumn{5}{|c|}{ Coffee Consumption in Men in HPFS (1986 Baseline) } & \multicolumn{5}{|c|}{ Coffee Consumption in Women in NHS (1980 Baseline) } \\
\hline & 0 cup/d & $<1 \mathrm{cup} / \mathrm{d}$ & $1-3$ cups/d & 4-5 cups/d & $\geq 6 \mathrm{cups} / \mathrm{d}$ & 0 cup/d & $<1 \mathrm{cup} / \mathrm{d}$ & $1-3 \mathrm{cup} / \mathrm{d}$ & 4-5 cups/d & $\geq 6$ cups $/ d$ \\
\hline Participants, $n$ & 12194 & 9445 & 15592 & 3494 & 1209 & 18691 & 7130 & 37219 & 14218 & 7018 \\
\hline Age, $y$ & 53 & 54 & 53 & 52 & 51 & 45 & 45 & 47 & 46 & 46 \\
\hline Family history of diabetes, \% & 13 & 13 & 13 & 14 & 12 & 19 & 19 & 18 & 18 & 19 \\
\hline Postmenopausal hormone use, \% & - & - & - & - & - & 17 & 18 & 17 & 14 & 13 \\
\hline Current smokers, \% & 6 & 7 & 11 & 20 & 31 & 19 & 21 & 25 & 41 & 56 \\
\hline Past smokers, \% & 33 & 41 & 47 & 50 & 43 & 26 & 28 & 30 & 28 & 21 \\
\hline Alcohol consumption, g/d & 7.8 & 10.6 & 13.8 & 14.8 & 15.6 & 4.5 & 5.5 & 7.2 & 7.5 & 6.8 \\
\hline Total caloric intake, kcal & 1937 & 1960 & 2027 & 2106 & 2200 & 1565 & 1551 & 1554 & 1578 & 1606 \\
\hline Polyunsaturated fat, $\% E$ & 5.9 & 5.9 & 5.9 & 6.0 & 6.0 & 5.3 & 5.3 & 5.2 & 5.3 & 5.4 \\
\hline Trans fatty acid, \%E & 1.2 & 1.2 & 1.3 & 1.4 & 1.4 & 2.2 & 2.2 & 2.2 & 2.3 & 2.3 \\
\hline Glycemic load & 131 & 125 & 121 & 115 & 112 & 88.7 & 85.4 & 83.0 & 80.5 & 79.6 \\
\hline Cereal fiber, $g / d$ & 6.4 & 5.9 & 5.6 & 5.3 & 4.8 & 2.5 & 2.4 & 2.4 & 2.4 & 2.3 \\
\hline Magnesium intake, $m g / d$ & 350 & 348 & 350 & 368 & 376 & 262 & 262 & 291 & 329 & 350 \\
\hline $\mathrm{BMI}, \mathrm{kg} / \mathrm{m}^{2}$ & 24.7 & 24.9 & 25.0 & 25.3 & 25.2 & 24.6 & 24.4 & 24.2 & 24.1 & 24.1 \\
\hline Physical activity, $h / w k$ & - & - & - & - & - & 4.0 & 3.9 & 3.9 & 3.8 & 3.6 \\
\hline Physical activity, MET/wk & 27.6 & 25.9 & 25.7 & 23.6 & 20.5 & - & - & - & - & - \\
\hline Total caffeine intake, $m g / d$ & 51 & 107 & 341 & 692 & 884 & 116 & 151 & 368 & 751 & 881 \\
\hline Tea, cups/d & 0.4 & 0.5 & 0.4 & 0.3 & 0.4 & 1.3 & 1.1 & 0.8 & 0.6 & 0.5 \\
\hline
\end{tabular}

* Values are means unless otherwise indicated. Data, except age, were directly standardized to the age distribution of each study sample. Statistical tests for the association

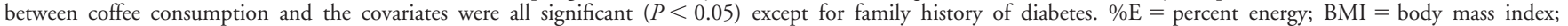
HPFS = Health Professionals Follow-up Study; MET = metabolic equivalent; NHS = Nurses' Health Study.

years of age); body mass index (weight divided by height $\left.\left[\mathrm{kg} / \mathrm{m}^{2}\right]\right)$ in 8 categories $(<23,23$ to 24,25 to 28,29 to 30,31 to 32,33 to 34,35 to 39 , or $\geq 40 \mathrm{~kg} / \mathrm{m}^{2}$ ); physical activity (hours of moderate or vigorous exercise in NHS or quintiles of metabolic equivalents in HPFS); family history of diabetes (yes or no); hormone use (never, current, or past [in NHS only]); smoking status (never, past, or current smokers [ 1 to 14,15 to 24 , or $\geq 25$ cigarettes per day]); alcohol consumption (0, 0.1 to $4.9,5$ to $9.9,10$ to 14.9 , or $\geq 15 \mathrm{~g} / \mathrm{d}$ ); total calorie intake (continuous); and quintiles of trans fat, glycemic load, and cereal fiber intake. We also adjusted for magnesium intake because our previous analyses have shown an inverse association between dietary magnesium and risk for diabetes (21). Information on covariates was updated periodically during follow-up. We performed a test for trend by treating median values of each category of caffeine and coffee intake as continuous variables.

To represent long-term intake of coffee and caffeine and to reduce measurement error, we conducted analyses using cumulative updated caffeine and coffee intake from all questionnaires (22). For example, in the NHS, diabetes incidence between 1980 and 1984 was related to the coffee intake from the 1980 questionnaire, and diabetes incidence between 1984 and 1986 was related to the average coffee intake from the 1980 and 1984 questionnaires. Secondary analyses using only information from baseline questionnaires yielded similar results.

\section{Role of the Funding Sources}

The funding sources had no role in the collection, analysis, or interpretation of the data or in the decision to submit the paper for publication.

\section{RESULTS}

The average consumption of regular coffee in the NHS decreased from 2.3 cups per day in 1980 to 1.6 cups per day in 1994. In the HPFS, the average consumption remained largely unchanged (1.4 cups per day in 1986 and 1.3 cups per day in 1994). We documented 1333 new cases of type 2 diabetes in men during 12 years of follow-up and 4085 new cases of type 2 diabetes in women during 18 years of follow-up. In both cohorts, higher coffee consumption was strongly associated with cigarette smoking and alcohol use (Table 1). Coffee intake was positively associated with intakes of total and saturated fats and magnesium and inversely associated with physical activity and intakes of cereal fiber, glycemic load, and tea. Coffee intake was not appreciably related to body mass index in either cohort.

After adjustment for age and body mass index, coffee consumption was associated with a statistically significantly lower risk for type 2 diabetes in both cohorts (Table 2). Further adjustment for physical activity, smoking, family history of diabetes, and other risk factors did not appreciably alter the results. The multivariate relative risks for diabetes according to coffee consumption categories $(0,<1,1$ to 3,4 to 5 , and $\geq 6$ cups per day) were $1.00,0.98,0.93$, 0.71 , and 0.46 (CI, 0.26 to $0.82 ; P=0.007$ for trend), respectively, in men and $1.00,1.16,0.99,0.70$, and 0.71 (CI, 0.56 to $0.89 ; P<0.001$ for trend), respectively, in women.

We observed a modest inverse association between decaffeinated coffee consumption and incidence of type 2 diabetes in both men and women (Table 2). In men, the multivariate relative risks according to consumption cate- 
ArTICLE $\quad$ Coffee and Diabetes Mellitus

Table 2. Relative Risk for Type 2 Diabetes Mellitus according to Coffee, Tea, and Decaffeinated Coffee Consumption*

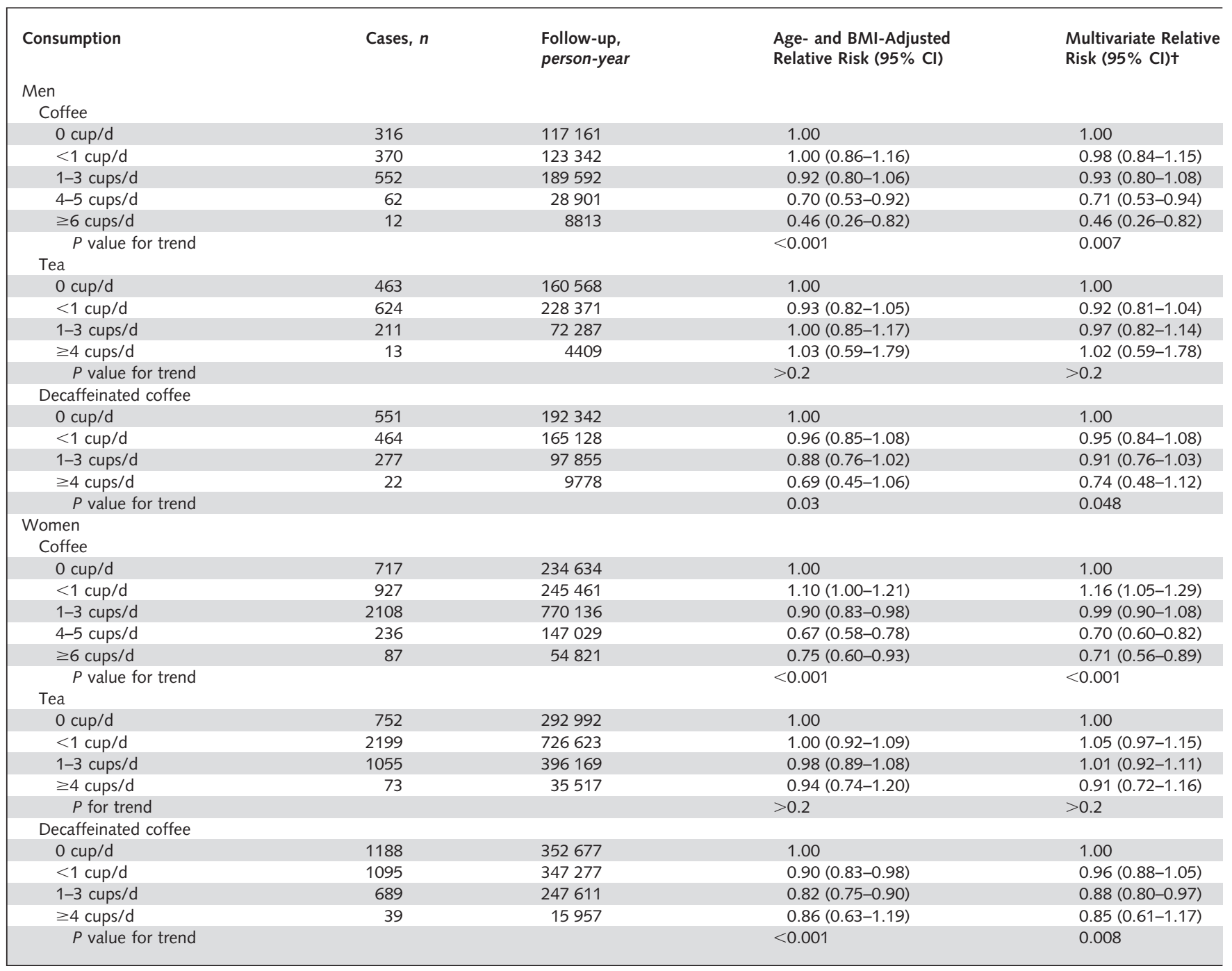

* The number of diabetes cases did not add up to the total because of missing data. The analyses on decaffeinated coffee in the Nurses' Health Study used 1984 as the baseline. BMI $=$ body mass index.

† Adjusted for age; total caloric intake; family history of diabetes; alcohol consumption (0, 0.1-4.9, 5-9.9, 10-14.9, 15-29.9, and $\geq 30 \mathrm{~g} / \mathrm{d}$ ); smoking status (never, past, and current $[1-14,15-24$, and $\geq 25$ cigarettes per day]); menopausal status and postmenopausal hormone use (women only); intakes of glycemic load, trans fat, polyunsaturated fatty acid, cereal fiber, and magnesium (all in quintiles); BMI (8 categories); and physical activity (hours of moderate or vigorous exercise per week for women and quintiles of metabolic equivalents in men).

gories $(0,<1,1$ to 3 , and $\geq 4$ cups per day) were 1.00 , $0.95,0.91$, and 0.74 (CI, 0.48 to $1.12 ; P=0.048$ for trend), respectively. The corresponding relative risks for women were $1.0,0.96,0.88$, and 0.85 (CI, 0.61 to 1.17 ; $P=0.008$ for trend), respectively. Adjustment for consumption of regular coffee did not appreciably alter these relative risks. Tea consumption was not statistically significantly associated with risk for diabetes in either cohort.

We observed a statistically significant inverse association between total caffeine intake and risk for type 2 diabetes in both men and women in age- and body mass index-adjusted analyses (Table 3). In multivariate analyses, we further adjusted for family history of diabetes, alcohol consumption, smoking, and several dietary factors (glycemic load, trans fat, polyunsaturated fatty acids, cereal fiber, and magnesium). These statistical adjustments had little effect on the results. For men, the multivariate relative risks across quintiles of caffeine intake $(0,<1,1$ to 3,4 to 5 , and $\geq 6$ cups per day) were $1.0,1.06,1.01,0.94$, and 0.80 (CI, 0.66 to $0.97 ; P=0.002$ for trend), respectively. The corresponding relative risks for women were 1.0, 1.02, $0.90,0.85$, and $0.70(\mathrm{CI}, 0.63$ to $0.79 ; P<0.001$ for trend), respectively. To evaluate the effects of noncoffee sources of caffeine, we examined the association between caffeine intake and risk for type 2 diabetes among noncoffee users and observed similar inverse association in both cohorts (multivariate relative risks comparing extreme quintiles were 0.71 [CI, 0.47 to 1.06 ] for men and 0.67 [CI, 0.48 to 0.92 ] for women). To examine whether the observed inverse association between regular coffee intake and type 2 diabetes was explained by caffeine intake, we simultaneously included coffee and caffeine in 1 model. The in- 
verse association for both coffee and caffeine intakes was persistent, suggesting that caffeine and other components of coffee contributed to the observed inverse association.

We conducted stratified analyses to evaluate whether the association between coffee consumption and type 2 diabetes varies according to body mass index, smoking, and physical activity (Table 4). The inverse association was present in both lean and obese participants, although the association seemed to be stronger among obese men than lean men $(P>0.2$ for interaction). Likewise, the inverse association between coffee consumption did not differ significantly between lean and obese women $(P=0.28$ for interaction). For both men and women, the inverse association between coffee consumption and risk for diabetes persisted in stratified analyses according to smoking status and levels of physical activity (Table 4). These analyses suggest that the inverse association between coffee consumption and diabetes risk was independent of lifestyle factors.

To minimize potential bias from subclinical disease, we conducted additional analyses by excluding cases of type 2 diabetes that occurred during the first 4 years of follow-up in the cohorts. The multivariate relative risks across categories of coffee consumption $(0,<1,1$ to 3,4 to 5 , and $\geq 6$ cups per day) were $1.0,0.94,0.90,0.64$, and $0.34(P=0.003$ for trend), respectively, for men and 1.0, $1.14,0.94,0.67$, and 0.73 ( $P<0.001$ for trend), respectively, for women. To address the possibility that surveillance varied according to coffee consumption, we performed an analysis restricted to cases reporting at least 1 symptom of diabetes at diagnosis. Results from this subgroup did not appreciably differ from those for the entire cohorts (multivariate relative risks were 1.0, 0.98, 0.93, 0.62 , and $0.45[P=0.006$ for trend $]$, respectively, for men and $1.0,1.20,1.02,0.74$, and $0.68[P<0.001$ for trend], respectively, for women).

\section{Discussion}

In these 2 large prospective cohorts of men and women, we found a statistically significant inverse association between coffee intake and risk for type 2 diabetes. These data are broadly consistent with a recent epidemiologic study of 17111 Dutch men and women 30 to 60 years of age (13). Our study, however, with a much larger sample size and longer follow-up, has extended the results of the Dutch study by examining the effects of total caffeine and different types of coffee. We found a modest inverse association between higher consumption of decaffeinated coffee and diabetes risk, but no statistically significant association was observed for tea consumption.

Metabolic studies have consistently shown that acute administration of caffeine can induce insulin resistance and impair glucose tolerance $(3,5-8)$. One potential mechanism involves caffeine blocking the effects of adenosine A1 receptor on glucose uptake in skeletal muscle. However, more recent studies suggest that the effects of caffeine on insulin sensitivity in vivo are mediated by elevated epinephrine levels rather than by peripheral adenosine receptor antagonism because caffeine-induced glucose intolerance can be abolished by $\beta$-adrenergic receptor blockade with propranolol (23).

The acute adverse effects of caffeine on insulin sensitivity raise some concern that long-term coffee intake may increase risk for type 2 diabetes (8). However, complete tolerance can develop after several days of caffeine use with respect to humoral and hemodynamic variables, including blood pressure, heart rate, plasma renin activity, plasma catecholamines, or urinary catecholamines $(12,24)$. Thus, the acute effects of caffeine on insulin sensitivity are probably transient and cannot be extrapolated to long-term use.

Caffeine increases basal energy expenditure; this thermogenic effect has a dose-response relationship with the

Table 3. Relative Risks for Type 2 Diabetes Mellitus according to Quintiles of Caffeine Intake*

\begin{tabular}{|c|c|c|c|c|c|}
\hline \multirow[t]{2}{*}{ Caffeine Intake } & $\begin{array}{l}\text { Median } \\
\text { Intake }\end{array}$ & Cases & Follow-up & $\begin{array}{l}\text { Age- and BMI-Adjusted } \\
\text { Relative Risk ( } 95 \% \mathrm{CI})\end{array}$ & $\begin{array}{l}\text { Multivariate Relative } \\
\text { Risk }(95 \% \mathrm{Cl})+\end{array}$ \\
\hline & $m g / d$ & $n$ & person-year & & \\
\hline \multicolumn{6}{|c|}{ Men in HPFS, 1986-1998 } \\
\hline$<37 \mathrm{mg} / \mathrm{d}$ & 13 & 235 & 94280 & 1.00 & 1.00 \\
\hline $37-120 \mathrm{mg} / \mathrm{d}$ & 74 & 294 & 94793 & $1.12(0.94-1.33)$ & $1.06(0.89-1.26)$ \\
\hline $121-240 \mathrm{mg} / \mathrm{d}$ & 172 & 296 & 94477 & $1.09(0.92-1.29)$ & $1.01(0.85-1.20)$ \\
\hline $241-417 \mathrm{mg} / \mathrm{d}$ & 323 & 272 & 94701 & $0.95(0.80-1.13)$ & $0.94(0.78-1.12)$ \\
\hline$>417 \mathrm{mg} / \mathrm{d}$ & 566 & 236 & 94661 & $0.83(0.69-0.99)$ & $0.80(0.66-0.97)$ \\
\hline $\begin{array}{c}P \text { value for trend } \\
\text { Women in NHS, 1980- }\end{array}$ & & & & $<0.001$ & 0.002 \\
\hline$<140 \mathrm{mg} / \mathrm{d}$ & 69 & 1011 & 290991 & 1.00 & 1.00 \\
\hline 140-257 mg/d & 193 & 984 & 290816 & $0.98(0.90-1.07)$ & $1.02(0.93-1.11)$ \\
\hline $258-376 \mathrm{mg} / \mathrm{d}$ & 328 & 808 & 290711 & $0.86(0.78-0.94)$ & $0.90(0.82-0.99)$ \\
\hline $377-534 \mathrm{mg} / \mathrm{d}$ & 432 & 728 & 291824 & $0.81(0.73-0.89)$ & $0.85(0.77-0.94)$ \\
\hline$>534 \mathrm{mg} / \mathrm{d}$ & 708 & 554 & 292020 & $0.70(0.63-0.77)$ & $0.70(0.63-0.79)$ \\
\hline$P$ value for trend & & & & $<0.001$ & $<0.001$ \\
\hline
\end{tabular}

* BMI = body mass index; HPFS = Health Professionals Follow-up Study; NHS = Nurses' Health Study.

+ Adjusted for the same covariates as in Table 2. 
Article Coffee and Diabetes Mellitus

Table 4. Multivariate Relative Risks for Type 2 Diabetes Mellitus according to Coffee Consumption Stratified by Body Mass Index, Smoking, and Physical Activity*

\begin{tabular}{|c|c|c|c|c|c|c|c|}
\hline \multirow[t]{2}{*}{ Variable } & \multicolumn{5}{|c|}{ Multivariate Risk according to Coffee Consumption $(95 \% \mathrm{Cl}) \dagger$} & \multirow{2}{*}{$\begin{array}{l}P \text { Value for } \\
\text { Trend }\end{array}$} & \multirow{2}{*}{$\begin{array}{l}P \text { Value for } \\
\text { Interaction }\end{array}$} \\
\hline & $0 \mathrm{cup} / \mathrm{wk}$ & $<1 \mathrm{cup} / \mathrm{wk}$ & $1-3$ cups/wk & $4-5$ cups/wk & $\geq 6$ cups/wk & & \\
\hline \multicolumn{8}{|l|}{ Men } \\
\hline \multicolumn{8}{|l|}{$\mathrm{BMI}$} \\
\hline$<25 \mathrm{~kg} / \mathrm{m}^{2}$ & 1.00 & $1.16(0.79-1.69)$ & $1.12(0.76-1.62)$ & $1.06(0.54-2.09)$ & $0.60(0.14-2.55)$ & $>0.2$ & \\
\hline $25-29.9 \mathrm{~kg} / \mathrm{m}^{2}$ & 1.00 & $1.01(0.81-1.26)$ & $0.88(0.71-1.08)$ & $0.68(0.46-1.03)$ & $0.56(0.26-1.22)$ & 0.01 & \\
\hline$\geq 30 \mathrm{~kg} / \mathrm{m}^{2}$ & 1.00 & $0.86(0.66-1.12)$ & $0.92(0.73-1.18)$ & $0.60(0.37-0.97)$ & $0.28(0.09-0.88)$ & 0.04 & \\
\hline & & & & & & & $>0.2$ \\
\hline \multicolumn{8}{|l|}{ Smoking status } \\
\hline Never & 1.00 & $1.01(0.80-1.28)$ & $0.95(0.75-1.20)$ & $0.65(0.36-1.16)$ & $0.40(0.10-1.61)$ & 0.10 & \\
\hline Past & 1.00 & $0.97(0.76-1.23)$ & $0.86(0.69-1.07)$ & $0.68(0.45-1.01)$ & $0.42(0.17-1.05)$ & 0.01 & \\
\hline Current & 1.00 & $1.01(0.52-1.94)$ & $1.26(0.73-2.20)$ & $0.86(0.40-1.84)$ & $0.34(0.08-1.49)$ & $>0.2$ & \\
\hline & & & & & & & $>0.2$ \\
\hline \multicolumn{8}{|l|}{ Physical activity } \\
\hline Low (<25 MET/wk) & 1.00 & $1.09(0.89-1.34)$ & $1.05(0.86-1.27)$ & $0.84(0.58-1.20)$ & $0.49(0.23-1.06)$ & 0.13 & \\
\hline \multirow[t]{2}{*}{ High ( $\geq 25$ MET/wk) } & 1.00 & $0.84(0.63-1.10)$ & $0.75(0.58-0.98)$ & $0.47(0.25-0.86)$ & $0.32(0.08-1.30)$ & 0.004 & \\
\hline & & & & & & & $>0.2$ \\
\hline \multicolumn{8}{|l|}{ Women } \\
\hline \multicolumn{8}{|l|}{ BMI } \\
\hline$<25 \mathrm{~kg} / \mathrm{m}^{2}$ & 1.00 & $1.32(0.97-1.79)$ & $1.02(0.77-1.34)$ & $0.67(0.42-1.05)$ & $0.51(0.25-1.06)$ & 0.004 & \\
\hline $25-29.9 \mathrm{~kg} / \mathrm{m}^{2}$ & 1.00 & $1.12(0.93-1.35)$ & $0.96(0.82-1.13)$ & $0.83(0.64-1.07)$ & $0.64(0.42-0.97)$ & 0.005 & \\
\hline$\geq 30 \mathrm{~kg} / \mathrm{m}^{2}$ & 1.00 & $1.15(1.01-1.31)$ & $0.96(0.86-1.08)$ & $0.59(0.47-0.74)$ & $0.79(0.58-1.07)$ & $<0.001$ & \\
\hline \multirow{2}{*}{\multicolumn{8}{|c|}{ Smoking status }} \\
\hline & & & & & & & \\
\hline Never & 1.00 & $1.30(1.14-1.49)$ & $1.02(0.90-1.15)$ & $0.72(0.54-0.95)$ & $0.34(0.17-0.69)$ & $<0.001$ & \\
\hline Past & 1.00 & $1.04(0.87-1.23)$ & $0.98(0.84-1.14)$ & $0.70(0.54-0.92)$ & $0.79(0.51-1.22)$ & 0.015 & \\
\hline Current & 1.00 & $0.92(0.67-1.25)$ & $0.90(0.70-1.14)$ & $0.64(0.47-0.87)$ & $0.77(0.54-1.11)$ & 0.012 & \\
\hline \multirow{2}{*}{\multicolumn{8}{|c|}{ Physical activity }} \\
\hline & & & & & & & \\
\hline Low $(<3.5 \mathrm{~h} / \mathrm{wk})$ & 1.00 & $1.22(1.07-1.39)$ & $1.07(0.95-1.20)$ & $0.65(0.52-0.80)$ & $0.85(0.64-1.13)$ & $<0.001$ & \\
\hline \multirow[t]{2}{*}{ High ( $\geq 3.5 \mathrm{~h} / \mathrm{wk})$} & 1.00 & $1.06(0.88-1.27)$ & $0.88(0.74-1.04)$ & 0.79 (0.59-1.05) & $0.60(0.36-1.00)$ & 0.003 & \\
\hline & & & & & & & $>0.2$ \\
\hline
\end{tabular}

* $\mathrm{BMI}=$ body mass index; MET $=$ metabolic equivalent.

+ Adjusted for the same covariates as Table 2, except for the stratification variable.

amount of caffeine consumed (10), and the magnitude of thermogenesis is greater in lean women than in obese women (11). Caffeine may also stimulate fat oxidation and mobilization of glycogen in muscle (25) and stimulate free fatty acid release (increased lipolysis) from peripheral tissues $(10,26)$. Ingestion of caffeine, alone or with ephedrine, decreases body weight in monkeys (27) and humans $(28,29)$. In our study, coffee consumption was not appreciably related to body mass index at baseline in either cohort. In addition, the inverse association between coffee and caffeine and risk for type 2 diabetes remained statistically significant after adjustment for body mass index, suggesting that the effects of coffee or caffeine are unlikely to be mediated through body weight.

Coffee contains many other ingredients that may contribute to the inverse association. For example, coffee contains a substantial amount of potassium; niacin; magnesium; and antioxidant substances, such as tocopherols and phenol chlorogenic acid (30). These constituents may have beneficial effects on the development of diabetes through synergistic or independent actions on glucose metabolism and insulin resistance. This could explain a modest inverse association between consumption of decaffeinated coffee and risk for diabetes observed in our study. Dietary intake of magnesium has been associated with a lower risk for type 2 diabetes in several epidemiologic studies $(21,31)$. In our study, the statistically significant inverse association for coffee persisted even after adjustment for magnesium intake. We considered the possibility that this inverse association was due to confounding by diet and lifestyle factors associated with coffee intake. Coffee consumption is frequently related to unhealthy behaviors, such as smoking, excessive consumption of alcohol, a poorer diet, and a sedentary lifestyle. The confounding effects of these variables would tend to bias the results toward a positive, not an inverse, association. In our study, we carefully controlled for these variables. Also, in stratified analyses, the inverse association between coffee intake and type 2 diabetes persisted in never and current smokers and in lean and obese participants.

Another potential concern is that persons with preexisting chronic diseases may avoid drinking coffee. However, this bias is unlikely to influence our results because we excluded participants with reported diabetes, cardiovascular disease, and cancer at baseline. Also, excluding incident diabetes cases that occurred in the first 4 years of follow-up 
did not affect the results, suggesting that preclinical diabetes is unlikely to have affected our analyses. When we used light coffee drinkers as the reference group, the relative risks for moderate and high categories of coffee consumption did not substantially change.

Because coffee consumption was self-reported by questionnaire, some misclassification of exposure is inevitable. However, such misclassification in prospective studies would have biased the results toward the null. Also, selfreport of coffee consumption has been extensively validated in subsamples of our cohorts. The use of repeated measures in the analyses not only accounts for changes in coffee use over time but also decreases measurement error.

In conclusion, these prospective data suggest a statistically significant inverse association between intakes of caffeine and regular coffee and incidence of diabetes in both men and women. This association is independent of body mass index, cigarette smoking, and other dietary and lifestyle factors. However, our observational study cannot prove a cause-effect relationship, and it is premature to recommend increased coffee drinking as a means to prevent type 2 diabetes. Further metabolic studies are required to investigate long-term effects of caffeine on glucose homeostasis, insulin resistance, and energy expenditure.

From Harvard School of Public Health, Channing Laboratory, Harvard Medical School, and Brigham and Women's Hospital, Boston, Massachusetts; and Mexican Institute of Social Security, Cuernavaca, Morelos, Mexico.

Acknowledgments: The authors thank Tricia Li for her expert assistance in data analysis.

Grant Support: By research grants DK58845, HL35464, AA11181, CA87969, and CA55075 from the National Institutes of Health.

Potential Financial Conflicts of Interest: None disclosed.

Requests for Single Reprints: Frank B. Hu, MD, PhD, Department of Nutrition, Harvard School of Public Health, 665 Huntington Avenue, Boston, MA 02115; e-mail, frank.hu@channing.harvard.edu.

Current author addresses and author contributions are available at www .annals.org.

\section{References}

1. Harris MI, Flegal KM, Cowie CC, Eberhardt MS, Goldstein DE, Little RR, et al. Prevalence of diabetes, impaired fasting glucose, and impaired glucose tolerance in U.S. adults. The Third National Health and Nutrition Examination Survey, 1988-1994. Diabetes Care. 1998;21:518-24. [PMID: 9571335]

2. Hu FB, Manson JE, Stampfer MJ, Colditz G, Liu S, Solomon CG, et al. Diet, lifestyle, and the risk of type 2 diabetes mellitus in women. N Engl J Med. 2001;345:790-7. [PMID: 11556298]

3. Keijzers GB, De Galan BE, Tack CJ, Smits P. Caffeine can decrease insulin sensitivity in humans. Diabetes Care. 2002;25:364-9. [PMID: 11815511]

4. Lundsberg LS. Coffeine consumption. In: Spiller GA, ed. Caffeine. Boca Raton, FL: CRC Pr; 1998:199-224.

5. Cheraskin E, Ringsdorf WM Jr. Blood-glucose levels after caffeine. Lancet. 1968;2:689. [PMID: 4175524]
6. Feinberg LJ, Sandberg H, De Castro O, Bellet S. Effects of coffee ingestion on oral glucose tolerance curves in normal human subjects. Metabolism. 1968; 17:916-22. [PMID: 4300352]

7. Graham TE, Sathasivam P, Rowland M, Marko N, Greer F, Battram D. Caffeine ingestion elevates plasma insulin response in humans during an oral glucose tolerance test. Can J Physiol Pharmacol. 2001;79:559-65. [PMID: 11478588]

8. Greer F, Hudson R, Ross R, Graham T. Caffeine ingestion decreases glucose disposal during a hyperinsulinemic-euglycemic clamp in sedentary humans. Diabetes. 2001;50:2349-54. [PMID: 11574419]

9. Dulloo AG, Geissler CA, Horton T, Collins A, Miller DS. Normal caffeine consumption: influence on thermogenesis and daily energy expenditure in lean and postobese human volunteers. Am J Clin Nutr. 1989;49:44-50. [PMID: 2912010]

10. Astrup A, Toubro S, Cannon S, Hein P, Breum L, Madsen J. Caffeine: a double-blind, placebo-controlled study of its thermogenic, metabolic, and cardiovascular effects in healthy volunteers. Am J Clin Nutr. 1990;51:759-67. [PMID: 2333832]

11. Bracco D, Ferrarra JM, Arnaud MJ, Jequier E, Schutz Y. Effects of caffeine on energy metabolism, heart rate, and methylxanthine metabolism in lean and obese women. Am J Physiol. 1995;269:E671-8. [PMID: 7485480]

12. Robertson D, Wade D, Workman R, Woosley RL, Oates JA. Tolerance to the humoral and hemodynamic effects of caffeine in man. J Clin Invest. 1981; 67:1111-7. [PMID: 7009653]

13. van Dam RM, Feskens EJ. Coffee consumption and risk of type 2 diabetes mellitus. Lancet. 2002;360:1477-8. [PMID: 12433517]

14. Grobbee DE, Rimm EB, Giovannucci E, Colditz G, Stampfer M, Willett W. Coffee, caffeine, and cardiovascular disease in men. N Engl J Med. 1990;323: 1026-32. [PMID: 2215561]

15. Colditz GA, Manson JE, Hankinson SE. The Nurses' Health Study: 20-year contribution to the understanding of health among women. J Womens Health. 1997;6:49-62. [PMID: 9065374]

16. Salvini S, Hunter DJ, Sampson L, Stampfer MJ, Colditz GA, Rosner B, Willett WC. Food-based validation of a dietary questionnaire: the effects of week-to-week variation in food consumption. Int J Epidemiol. 1989;18:858-67. [PMID: 2621022]

17. Classification and diagnosis of diabetes mellitus and other categories of glucose intolerance. National Diabetes Data Group. Diabetes. 1979;28:1039-57. [PMID: 510803]

18. Manson JE, Colditz GA, Stampfer MJ, Willett WC, Krolewski AS, Rosner $\mathrm{B}$, et al. A prospective study of maturity-onset diabetes mellitus and risk of coronary heart disease and stroke in women. Arch Intern Med. 1991;151:1141-7. [PMID: 2043016]

19. Field AE, Coakley EH, Must A, Spadano JL, Laird N, Dietz WH, et al. Impact of overweight on the risk of developing common chronic diseases during a 10-year period. Arch Intern Med. 2001;161:1581-6. [PMID: 11434789]

20. Cox DR, Oakes D. Analysis of Survival Data. London: Chapman and Hall; 1984.

21. Salmeron J, Manson JE, Stampfer MJ, Colditz GA, Wing AL, Willett WC. Dietary fiber, glycemic load, and risk of non-insulin-dependent diabetes mellitus in women. JAMA. 1997;277:472-7. [PMID: 9020271]

22. Hu FB, Stampfer MJ, Manson JE, Rimm E, Colditz GA, Rosner BA, et al. Dietary fat intake and the risk of coronary heart disease in women. N Engl J Med. 1997;337:1491-9. [PMID: 9366580]

23. Thong FS, Graham TE. Caffeine-induced impairment of glucose tolerance is abolished by beta-adrenergic receptor blockade in humans. J Appl Physiol. 2002; 92:2347-52. [PMID: 12015346]

24. Brown CR, Benowitz NL. Caffeine and cigarette smoking: behavioral, cardiovascular, and metabolic interactions. Pharmacol Biochem Behav. 1989;34: 565-70. [PMID: 2623013]

25. Spriet LL, MacLean DA, Dyck DJ, Hultman E, Cederblad G, Graham TE. Caffeine ingestion and muscle metabolism during prolonged exercise in humans. Am J Physiol. 1992;262:E891-8. [PMID: 1616022]

26. Ryu S, Choi SK, Joung SS, Suh H, Cha YS, Lee S, et al. Caffeine as a lipolytic food component increases endurance performance in rats and athletes. J Nutr Sci Vitaminol (Tokyo). 2001;47:139-46. [PMID: 11508705]

27. Ramsey JJ, Colman RJ, Swick AG, Kemnitz JW. Energy expenditure, body 6 January $2004 \mid$ Annals of Internal Medicine $\mid$ Volume $140 \bullet$ Number $1 \mid \mathbf{7}$ 
composition, and glucose metabolism in lean and obese rhesus monkeys treated with ephedrine and caffeine. Am J Clin Nutr. 1998;68:42-51. [PMID: 9665095] 28. Astrup A, Breum L, Toubro S, Hein P, Quaade F. The effect and safety of an ephedrine/caffeine compound compared to ephedrine, caffeine and placebo in obese subjects on an energy restricted diet. A double blind trial. Int J Obes Relat Metab Disord. 1992;16:269-77. [PMID: 1318281]

29. Boozer CN, Daly PA, Homel P, Solomon JL, Blanchard D, Nasser JA, et al. Herbal ephedra/caffeine for weight loss: a 6-month randomized safety and efficacy trial. Int J Obes Relat Metab Disord. 2002;26:593-604. [PMID: 12032741]

30. Devasagayam TP, Kamat JP, Mohan H, Kesavan PC. Caffeine as an antioxidant: inhibition of lipid peroxidation induced by reactive oxygen species. Biochim Biophys Acta. 1996;1282:63-70. [PMID: 8679661]

31. Meyer KA, Kushi LH, Jacobs DR Jr, Slavin J, Sellers TA, Folsom AR. Carbohydrates, dietary fiber, and incident type 2 diabetes in older women. Am J Clin Nutr. 2000;71:921-30. [PMID: 10731498]

Here is another false concept often heard from the lips of the newly graduated:

"Everything of major importance in the various areas of science has already been clarified. What difference does it make if I add some minor detail or gather up what is left in some field where more diligent observers have already collected the abundant, ripe grain. Science won't change its perspective because of my work, and my name will never emerge from obscurity."

This is often indolence masquerading as modesty. . . It is fair to say that, in general, no problems have been exhausted; instead men have been exhausted by the problems. Soil that appears impoverished to one researcher reveals its fertility to another. Fresh talent approaching the analysis of a problem without prejudice will always see new possibilities. ...

Santiago Ramon y Cajal

Advice for a Young Investigator

Neely Swanson and Larry W. Swanson, tr.

Cambridge, MA: MIT Pr; 1999:12-3.

Submitted by:

Michael K. Paasche-Orlow, MD, MPH

Frederick L. Bancati, MD, MHS

The Johns Hopkins Medical Institutions

Baltimore, MD 21205-2223

Submissions from readers are welcomed. If the quotation is published, the sender's name will be acknowledged. Please include a complete citation (along with page number on which the quotation was found), as done for any reference.-The Editor 
Current Author Addresses: Dr. Salazar-Martinez: National Institute of Public Health, Av. Universidad 655, Col. Sta. Maria Ahuacatitlánin, 62508 Cuernavaca, Morelos, Mexico.

Drs. Willett, Ascherio, and Hu: Department of Nutrition, Harvard School of Public Health, 665 Huntington Avenue, Boston, MA 02115. Dr. Manson: Division of Preventive Medicine, Department of Medicine, Harvard Medical School and Brigham and Women's Hospital, 900 Commonwealth Avenue, 3rd Floor, Boston, MA 02215.

Dr. Leitzmann: Division of Cancer Epidemiology and Genetics, National Cancer Institute, National Institutes of Health, MSC 7232, Bethesda, MD 20892.

Dr. Stampfer: Harvard School of Public Health, 677 Huntington Avenue, Boston, MA 02115.

Author Contributions: Conception and design: E. Salazar-Martinez, W.C. Willett, A. Ascherio, J.E. Manson, M.F. Leitzmann, F.B. Hu.
Analysis and interpretation of the data: E. Salazar-Martinez, W.C. Willett, A. Ascherio, J.E. Manson, M.F. Leitzmann, M.J. Stampfer, F.B. Hu.

Drafting of the article: E. Salazar-Martinez, F.B. Hu.

Critical revision of the article for important intellectual content: E. Salazar-Martinez, W.C. Willett, A. Ascherio, J.E. Manson, M.F. Leitzmann, M.J. Stampfer, F.B. Hu.

Final approval of the article: E. Salazar-Martinez, A. Ascherio, J.E. Manson, M.F. Leitzmann, M.J. Stampfer, F.B. Hu.

Statistical expertise: M.F. Leitzmann, M.J. Stampfer, F.B. Hu.

Obtaining of funding: W.C. Willett, J.E. Manson, F.B. Hu.

Administrative, technical, or logistic support: J.E. Manson, F.B. Hu. Collection and assembly of data: J.E. Manson, F.B. Hu. 